\title{
A neurotoxicidade da Cannabis sativa e suas repercussões sobre a morfologia do tecido cerebral
}

\section{Cannabis sativa neurotoxicity and impacts on the brain tissue morphology}

\author{
Bárbara da Silva Santos ${ }^{1}$, Marcelo Coertjens ${ }^{2}$
}

${ }^{1}$ Curso de Biomedicina da Universidade Federal do Piauí (UFPI) - Parnaíba (PI), Brasil.

${ }^{2}$ Curso de Fisioterapia da UFPI - Parnaíba (PI), Brasil.

DOI: http://dx.doi.org/10.7322/abcshs.v39i1.250

\section{RESUMO}

Para a compreensão das repercussões psicológicas e comportamentais verificadas em usuários de Cannabis sativa, experimentos têm sido desenvolvidos analisando a relação entre a intensidade do uso da droga e biomarcadores de lesão e inflamação. Dessa forma, este estudo teve como objetivo realizar pesquisa bibliográfica, relacionando marcadores bioquímicos de neurotoxicidade e suas repercussões sobre a morfologia do tecido cerebral em usuários de Cannabis sativa, durante a exposição ao $\triangle 9$-THC por via intravenosa e em pesquisas in vitro. Trata-se de uma revisão narrativa cuja pesquisa bibliográfica foi realizada nos bancos de dados PubMed, SciELO e Google Acadêmico, utilizandose como critério de inclusão os seguintes termos: "Cannabis sativa", "marijuana", "maconha", " $\Delta 9-T H C "$, "neurotrophins", "neurotrofinas", "prostaglandins", "prostaglandinas", "BDNF" e "NGF". Dessa forma, foram selecionados 40 artigos para integrar a presente revisão, datados de 1987 a 2013. O período de realização da pesquisa bibliográfica foi de agosto de 2011 a maio de 2013. Foi possivel identificar os tipos e a magnitude das alterações morfológicas e bioquímicas decorrentes do uso de Cannabis sativa ou da exposição ao $\triangle 9$-THC. De uma forma geral, foi constatada a diminuição das massas cinzenta e branca do cérebro, da densidade do hipocampo, do volume das células neurais, entre outros. Foram constatadas também alterações nos níveis séricos de neurotrofinas e na biossíntese de prostaglandinas, de acordo com a metodologia utilizada ou região avaliada. Esses achados poderiam estar relacionados às mudanças comportamentais observadas em usuários de Cannabis sativa, esclarecendo, por exemplo, diversos sintomas psíquicos relatados na literatura.

Palavras-chave: Cannabis sativa; tetra-hidrocanabinol; traumatismos encefálicos; fatores de crescimento neural; prostaglandinas.

\section{ABSTRACT}

In order to understand psychological and behavioral impact among Cannabis sativa users, experiments have been developed by analyzing the relationship between the intensity of the use with injury and inflammation biomarkers. Therefore, this paper aimed to carry out a literature review, relating biochemical markers of neurotoxicity and their impact on morphology of brain tissue in Cannabis sativa users, during the exposure to $\Delta 9$-THC intravenously and in in vitro studies. This is a narrative review whose bibliographic research was managed in PubMed, SciELO and Google Scholar databases, using the following terms as inclusion criterion: "Cannabis sativa", "marijuana", "maconha", " $\triangle 9$-THC", "neurotrophins", "neurotrofinas", "prostaglandins", "prostaglandinas", "BDNF" and "NGF". Thereby, 40 articles were selected to integrate the present review, dated from 1987 to 2013. The period of this literature review was from August 2011 to May 2013. It was possible to identify the types and the magnitude of morphological and biochemical changes resulting from the Cannabis sativa use or exposure to $\Delta 9$-THC. In general, a reduction was found in gray and white brain mass, in density of hippocampus, in the volume of nerve cells, among others. We also observed changes in serum levels of neurotrophins and in prostaglandin biosynthesis, in accordance with methodology used or the evaluated area. These findings could be related to behavioral changes observed in Cannabis sativa users, clarifying, for instance, many psychological symptoms reported in literature.

Keywords: Cannabis sativa; tetrahydrocannabinol; brain injuries; nerve growth factors; prostaglandins. 


\section{INTRODUÇÃO}

Durante séculos, a Cannabis sativa vem sendo consumida mundialmente com uma prevalência de uso que fica atrás somente do consumo de álcool e de nicotina, se tornando, assim, a droga ilícita mais utilizada no mundo ${ }^{1}$. Sua constituição possui mais de 400 componentes diferentes e, aproximadamente, 60 destes se ligam aos receptores canabinoides, CB1 e CB2, presente em animais. Dentre esses componentes, o delta 9-tetra-hidrocanabinol ( $\Delta 9$-THC) é o principal constituinte psicoativo, estando relacionado com efeitos subjetivos, tais como euforia, sedação, alteração nas funções sensoriais, prejuízo no controle motor, no aprendizado e na memória ${ }^{2}$.

Nos últimos anos, o $\Delta 9$-THC tem sido alvo de inúmeros estudos relacionados a seus efeitos colaterais em usuários de Cannabis. Como demonstrado por Chan et al. ${ }^{3}$, o uso crônico da Cannabis provoca rupturas dos filamentos de DNA e alterações na morfologia neural, incluindo diminuição da densidade e volume dos neurônios do hipocampo. Outras pesquisas confirmam degeneração dendrítica em diferentes regiões do hipocampo ${ }^{4}$, diminuição da matéria branca frontal ${ }^{5}$ e redução do volume da amígdala ${ }^{6}$, sugerindo-se, então, uma relação entre a neurotoxicidade apresentada em usuários da Cannabis com o excesso de $\Delta 9$-THC em regiões cerebrais. Para a compreensão dos mecanismos de neurotoxicidade demonstrados pela droga, experimentos envolvendo a mensuração de biomarcadores de lesão e inflamação têm sido desenvolvidos a fim de relacionar a intensidade do uso da droga com a detecção de uma possível lesão.

As pesquisas relacionando o nível desses biomarcadores com o uso crônico da Cannabis sativa têm desvendado o mecanismo de ação e os efeitos que seu princípio ativo provoca no organismo. Exemplos de biomarcadores são o fator neurotrófico derivado do cérebro (BDNF) e o fator de crescimento neural (NGF), ambas neurotrofinas expressas em múltiplos tipos celulares, principalmente nos neurônios e células da glia ${ }^{7}$. O BDNF atua na neuroplasticidade ${ }^{8}$, enquanto que o NGF previne a degeneração dos nervos periféricos ${ }^{9}$; tais ações conferem funções protetoras a ambas as neurotrofinas. Por exemplo, D'Souza et al. ${ }^{8}$ demonstraram o comportamento do BDNF sérico após exposição intravenosa ao $\Delta$ 9-THC, comparando um grupo controle saudável de usuários agudos de Cannabis com um grupo de usuários crônicos. Os resultados demonstraram um aumento nos níveis séricos de BDNF em controles agudos, expressando uma tentativa de neuroproteção, enquanto os usuários crônicos mostraram um nível menor dessa neurotrofina, representando a diminuição de suas funções.

Além de avaliar a repercussão na neuroproteção, estudos referem-se também a marcadores inflamatórios para a descrição dos efeitos provocados pela exposição ao $\Delta 9$-THC. Chan et al. ${ }^{3}$ demonstraram que a liberação de ácido araquidônico (AA) está diretamente associado à dose de $\Delta 9$-THC, provocando, consequentemente, uma resposta inflamatória. Esse fato tem demonstrado que o $\Delta$ 9-THC pode atuar como um potencializador dos produtos da cascata do AA, incluindo as prostaglandinas (PG), tromboxanos (TX) e leucotrienos (LT). A biossíntese e os níveis das PGs aumentam com a exposição a canabinoides e estes expressam seus efeitos com a elevação na produção de PGs ${ }^{10}$. Estudos demonstram que tais efeitos podem ser reduzidos com o uso de agentes anti-inflamatórios não esteroidais (AINES), que são potentes inibidores da biossíntese de $\mathrm{PGs}^{3}$. Apesar de as pesquisas citadas comprovarem a repercussão degenerativa do princípio ativo sobre a morfologia e funcionalidade das células nervosas, existem, por outro lado, evidências demonstrando efeitos neuroprotetores através da ativação dos produtos das lipo-oxigenases por meio da estimulação da anandamida, um eicosanoide que mimetiza o $\Delta 9-\mathrm{THC}^{11}$. Neste sentido, nosso objetivo foi realizar pesquisa bibliográfica relacionando marcadores bioquímicos de neurotoxicidade e suas repercussões sobre a morfologia do tecido cerebral em usuários de Cannabis sativa, bem como durante a exposição ao $\Delta$ 9-THC por via intravenosa e em pesquisas in vitro.

\section{MÉTODOS}

Este estudo trata-se de uma revisão narrativa cuja pesquisa bibliográfica foi realizada nos bancos de dados PubMed, SciELO e Google Acadêmico. Os termos utilizados foram: "Cannabis sati$v a$ ", "marijuana”, "maconha", “ $\Delta 9-\mathrm{THC}$ ", "neurotrophins", "neurotrofinas", "prostaglandins", "prostaglandinas", "BDNF” e "NGF”. Foram encontrados variados artigos que abordavam itens da temática desta revisão. Como critério de inclusão, cada artigo deveria tratar do uso da Cannabis associado com mudanças morfológicas e alterações nos níveis de neurotrofinas ou prostaglandinas no soro ou no Sistema Nervoso Central (SNC). Foram excluídos os artigos que não relacionavam os itens mencionados anteriormente. Além disso, foram excluídos também os artigos menos significativos para a adequação às normas da presente revista. Dessa forma, foram selecionados 40 artigos para integrar a presente revisão, datados de 1987 a 2013. O período de realização da pesquisa bibliográfica foi de agosto de 2011 a maio de 2013. Nesta pesquisa, não houve restrição quanto à língua, sendo incluídos artigos na língua portuguesa e inglesa.

\section{RESULTADOS E DISCUSSÃO}

\section{Alterações morfológicas no tecido cerebral em usuários de Cannabis}

O $\Delta$ 9-THC é o principal constituinte da Cannabis e está diretamente relacionado com receptores canabinoides CB1 e CB2, localizados em diferentes partes do corpo. A ativação desses receptores pela exposição crônica ao $\Delta 9$-THC ou por agonistas análogos no tecido cerebral pode desenvolver diversas alterações. $\mathrm{O}$ avanço de tecnologias de neuroimagem e nos métodos de análise de imagem tem oferecido um poderoso instrumento para o estudo direto dos efeitos da Cannabis na estrutura e funcionamento cerebral, aumentando a sensibilidade para a mensuração regional ou global 
das substâncias branca e cinzenta. Portanto, vários autores realizaram seus estudos utilizando técnicas para a visualização da proporção dos volumes cerebrais, com o intuito de verificar os efeitos morfológicos causados pela exposição à Cannabis.

Segundo os estudiosos, tais mudanças estruturais poderiam estar diretamente correlacionadas com os efeitos colaterais observados em usuários crônicos da Cannabis, como diminuição na atenção seletiva, alteração nas funções sensoriais, prejuízo do controle motor, do aprendizado e prejuízo transitório na memória de curto prazo $^{2}$. Além de efeitos adversos que incluem ataques de pânico, crises de ansiedade, acentuação de sintomas psicóticos existentes e o desenvolvimento de psicose em indivíduos sadios ${ }^{6}$.

\section{Estudos realizados com técnicas de neuroimagem}

Alguns desses estudos demonstraram diminuição na densidade da substância branca ou cinzenta ${ }^{12}$ ou em áreas do parahipocampo $^{13}$. Em uma pesquisa recente, Yücel et al. ${ }^{6}$ evidenciaram alterações cerebrais estruturais em usuários de Cannabis utilizando o método de ressonância magnética (RM). Foram observadas reduções significativas nos volumes bilaterais do hipocampo (12\%) e diminuição no volume da amígdala (7\%). Tal estudo foi realizado em adultos com uma média de 20 anos de uso diário da droga, comparados a controles não usuários e pareados por idade, sexo e quociente de inteligência. As alterações foram mais significativas quanto maiores eram as doses de exposição à Cannabis, sendo estas mais frequentemente localizadas na região do hipocampo. Resultados semelhantes foram encontrados nos estudos de Wilson et al. ${ }^{12}$ e Matochik et al. ${ }^{13}$ apesar de seus usuários de Cannabis terem sofrido uma exposição bem menor à droga e terem sido utilizadas técnicas menos sensíveis para a realização dos exames em comparação ao estudo de Yücel et al. ${ }^{6}$.

Block et al. ${ }^{14}$ utilizaram, igualmente, técnicas de RM e examinaram 18 usuários frequentes de Cannabis em comparação com 13 não usuários. Diferentemente dos estudos previamente citados, nesse não foi observada anormalidade neuroestrutural, atrofia cerebral ou mudanças globais ou regionais nos volumes dos tecidos dos usuários de Cannabis. Entretanto, de modo surpreendente, os volumes ventriculares nos usuários foram menores do que nos controles, o que pode sugerir o desenvolvimento de hipertensão intracraniana. Diante dos achados de seus respectivos estudos, os autores concluíram, de uma maneira geral, que a exposição ao $\triangle 9$-THC afeta a morfologia cerebral, mais frequentemente quando a Cannabis é utilizada em tempo prolongado. Ou seja, embora o uso moderado não possa levar a efeitos neurotóxicos significativos, tais resultados sugerem que o uso diário é prejudicial para o tecido cerebral humano, especialmente nas regiões médio-temporais ${ }^{6}$.

A diminuição do volume do hipocampo pode estar estreitamente relacionada com o aparecimento de sintomas psicóticos ou pode refletir o desenvolvimento de doença mental em usuários crônicos que possuam uma pré-disponibilidade a certas doenças, assim como foi observado no estudo de Yücel et al. ${ }^{6}$, no qual foi demonstrada uma acentuação de sintomas depressivos em usuários que apresentavam o histórico da doença. E quanto à associação da redução bilateral do volume da amígdala com o uso da Cannabis, não foi observada qualquer relação com sintomas psicóticos ou associações depressivas, porém a perda da aprendizagem emocional e prejuízo na memória de curto prazo estavam fortemente correlacionados.

Com o mesmo objetivo de verificar a existência de diferenças estruturais cerebrais em pacientes usuários de Cannabis, Schlaepfer et al. ${ }^{5}$ reuniram 16 usuários em grupos por idade, sexo e raça com seus respectivos controles pareados. Os 32 pacientes foram submetidos em um scanner de RM. Os resultados demonstraram que os usuários de Cannabis tiveram porcentagem de volume de matéria branca significativamente menor do que os controles, em ambas as metodologias utilizadas no estudo, segmentação e estereologia. Os autores do estudo sugerem que essa diferença de volumes poderia ter sido causada pelo efeito neurotóxico direto da droga na substância branca, uma anormalidade pré-existente no desenvolvimento do lobo frontal ou uma combinação de ambos os efeitos.

A relação entre o uso de Cannabis, funcionamento e morfologia cerebral foi também estudada em 57 usuários crônicos da droga, 32 homens e 25 mulheres ${ }^{12}$. Os autores mediram os volumes cerebrais tais como o volume dos ventrículos, substância branca e cinzenta e cérebro total. A análise indicou que os indivíduos que começaram a usar Cannabis durante a adolescência, antes dos 17 anos de idade, comparados com aqueles que começaram depois, apresentavam menor porcentagem de substância cinzenta cortical, com significativa diferença nos lobos frontais. Os mesmos pacientes também apresentavam maior porcentagem de substância branca cerebral. Esses achados não se relacionaram com os resultados de Schlaepfer et al. ${ }^{5}$, mas ambos os grupos de pesquisadores explicam as alterações nos lobos frontais por um possível efeito neurotóxico da Cannabis no tecido cerebral. Wilson et al. ${ }^{12}$ complementam lançando a hipótese de que essas diferenças seriam causadas pelos efeitos da Cannabis nos hormônios gonadais e pituitários e seu consequente efeito no desenvolvimento do cérebro.

Historicamente, outras técnicas têm sido utilizadas para avaliar os efeitos crônicos do consumo da Cannabis, tais como as técnicas de tomografia computadorizada (TC). Crippa et al. ${ }^{2}$ compararam pesquisas mais antigas e verificaram que a TC tem se mostrado menos sensível do que a RM em detectar alterações cerebrais, demonstrado alterações não significativas ou até mesmo nenhuma em usuários crônicos de Cannabis.

\section{Estudos realizados com técnicas in vitro}

Para determinar se o $\Delta 9$-THC causa neurotoxicidade e para analisar a viabilidade e morfologia das células neurais diante do mesmo, alguns autores desenvolveram modelos de pesquisas in vitro como forma de verificar o mecanismo de ação do $\Delta$ 9-THC, permitindo esclarecer muitas das alterações cerebrais 
proporcionadas pela exposição crônica a Cannabis. Neste sentido, Chan et al. ${ }^{3}$ realizaram estudo utilizando o cultivo de células neurais do hipocampo de ratos. De acordo com os autores, tal procedimento foi justificado em virtude de o hipocampo ser uma região cerebral rica na concentração de receptores CB1. Foi constatada significativa diminuição da densidade neural das células do hipocampo. Além disso, foi destacada a diminuição do volume médio das células neurais e de seus núcleos, da densidade sináptica e do comprimento dendrítico de neurônios piramidais do CA3, um subcampo do hipocampo. Rupturas dos filamentos de DNA genômico e presença de apoptose neural também foram detectadas neste estudo ${ }^{3}$.

Os resultados apresentados na pesquisa anterior foram semelhantes aos dos estudos de Scallet et al..$^{15}$ e Landfield et al. ${ }^{16}$. Técnicas morfométricas foram utilizadas para investigar os efeitos crônicos do $\Delta 9$-THC sobre a integridade anatômica do hipocampo de ratos que receberam oralmente 10 a $60 \mathrm{mg} / \mathrm{kg}$ de $\Delta 9-\mathrm{THC}$ ao longo de 90 dias. Seus resultados apresentaram uma redução significativa de $44 \%$ no número de sinapses do hipocampo ${ }^{15}$. Por conseguinte, Landfield et al. ${ }^{16}$ realizaram também análises morfométricas em estudos de microscopia eletrônica em cérebros de 21 ratos tratados cronicamente com $8 \mathrm{mg} / \mathrm{kg}$ de $\Delta 9$-THC (cinco vezes por semana, durante quatro meses) e em 36 ratos tratados com $4 \mathrm{mg} / \mathrm{kg}$ de $\Delta 9$-THC (cinco vezes por semana, durante oito meses). Neste estudo, observou-se significativa diminuição da densidade neuronal e da densidade sináptica das células piramidais do hipocampo induzidas pelo $\Delta 9$-THC. Verificou-se também aumento da reatividade das células da glia, ou seja, um aumento de inclusões citoplasmáticas.

Com o mesmo objetivo de observar e avaliar mudanças morfológicas no hipocampo, Lawston et al. ${ }^{4}$ desenvolveram um estudo no qual ratos recebiam duas injeções diárias de WIN 55,2122, um agonista de receptores CB1 análogo ao $\Delta 9$-THC. No $22^{\circ}$ dia de experiência, os cérebros dos animais em estudo, tanto do grupo tratado com o agonista como do grupo controle saudável, foram fatiados e adicionados a MAP-2, uma proteína de microtúbulos encontrada nos dendritos e utilizada para a quantificação e visualização dos mesmos no método de coloração imunohistoquímica, sendo o comprimento dos dendritos determinado através de capturas de imagem.

Foi observado que a coloração imunoquímica de dendritos com a proteína MAP-2 foi significativamente menor nos animais saudáveis, demonstrando os dendritos como finos processos contínuos, diferentemente dos animais tratados, que mostraram uma aparente desorganização dos dendritos dentro do CA1, um subcampo do hipocampo ${ }^{4}$. O comprimento total dendrítico em CA1 foi diminuído, demonstrando mudanças morfológicas específicas nos animais tratados. Nestes, os dendritos de CA1 aparecem como segmentos desconexos, diferentes de estruturas contínuas, como observadas nos animais controles. Assim, foi observado que o CA1 foi a região do hipocampo que mais se mostrou sensível ao WIN 55,212-2.
Apesar das mudanças morfológicas verificadas, tais como diminuição no comprimento dos dendritos e desorganização dos mesmos dentro do hipocampo, não houve perda celular ${ }^{4}$. Ou seja, houve degeneração dendrítica, demonstrada nas imagens como segmentos desconexos, mas sem a ocorrência de morte neural. De acordo com seus estudos, os autores levantaram a hipótese de que os efeitos conhecidos da Cannabis e de seus análogos na aprendizagem e memória estariam diretamente associados às alterações morfológicas no hipocampo.

Neste sentido, podemos constatar como efeitos da ação do $\triangle 9$-THC a ocorrência de sérias alterações morfológicas no tecido cerebral, visto que os estudos analisados são, em grande parte, voltados para a análise dos efeitos colaterais causados pelo uso da Cannabis (Tabela 1). A maioria dos trabalhos in vitro demonstraram diminuição no volume médio das células neurais, redução na densidade neuronal e diminuição no comprimento dendrítico. Esses achados se relacionam com os resultados encontrados nas pesquisas de neuroimagem, que demonstram significativas diminuições nas densidades das massas cinzenta e branca do cérebro. Neste sentido, pode-se observar adaptações morfológicas utilizando técnicas diferentes de pesquisa. Além disso, é importante ressaltar que essas alterações morfológicas podem desencadear mudanças comportamentais e cognitivas na forma de prejuízo da memória de curto prazo, perda da aprendizagem emocional, acentuação de sintomas depressivos em usuários com pré-disposição à depressão $0^{6}$, entre outros efeitos.

Tabela 1: Alterações morfológicas no tecido cerebral verificadas por meio de estudos de neuroimagens após o consumo de Cannabis sativa e pesquisas in vitro após exposição ao $\Delta 9-\mathrm{THC}$

\begin{tabular}{|c|c|}
\hline Autores & Alterações morfológicas cerebrais \\
\hline Chan et al..$^{3 *}$ & $\begin{array}{l}\text { Diminuição do volume médio das células neurais } \\
\text { e de seus núcleos; redução da densidade } \\
\text { sináptica e do comprimento dendrítico de } \\
\text { neurônios piramidais do subcampo CA3 do } \\
\text { hipocampo, rupturas dos filamentos de DNA } \\
\text { genômico e presença de apoptose neural. }\end{array}$ \\
\hline Lawston et al. ${ }^{4 *}$ & $\begin{array}{l}\text { Redução no comprimento dos dendritos e } \\
\text { desorganização dos mesmos dentro do hipocampo. }\end{array}$ \\
\hline Schlaepfer et al..$^{5 * \star}$ & $\begin{array}{l}\text { Diminuição da densidade das substâncias } \\
\text { branca e cinzenta. }\end{array}$ \\
\hline Yücel et al..$^{6 * *}$ & $\begin{array}{l}\text { Diminuição dos volumes bilaterais do } \\
\text { hipocampo e do volume das amígdalas. }\end{array}$ \\
\hline Wilson et al. ${ }^{12 \star *}$ & $\begin{array}{l}\text { Diminuição da densidade das substâncias } \\
\text { branca e cinzenta. }\end{array}$ \\
\hline Matochik et al. ${ }^{13 * *}$ & $\begin{array}{l}\text { Diminuição na densidade do parahipocampo, } \\
\text { massa cinzenta e matéria branca do cérebro. }\end{array}$ \\
\hline Block et al. ${ }^{14 * *}$ & Redução nos volumes ventriculares. \\
\hline Scallet et al. ${ }^{15 *}$ & Diminuição no número de sinapses. \\
\hline Landfield et al. ${ }^{16 *}$ & $\begin{array}{l}\text { Diminuição da densidade neuronal e aumento } \\
\text { da reatividade das células da glia. Aumentos na } \\
\text { atividade da hipófise durante estresse, elevação } \\
\text { dos níveis dos hormônios adrenocorticotrópico } \\
\text { (ACTH) e corticosterona. }\end{array}$ \\
\hline
\end{tabular}

*Pesquisas in vitro por exposição ao $\triangle 9$-THC ou um agonista análogo ao $\triangle 9$-THC; **pesquisas avaliando e efeito do consumo de Cannabis sativa DNA: ácido desoxirribonucleico 
Com o desenvolvimento de novas técnicas de estudo, os pesquisadores podem verificar também as repercussões bioquímicas no tecido cerebral com a exposição do $\Delta 9$-THC e quais substâncias apresentam maior sensibilidade ao princípio ativo da Cannabis esclarecendo, dessa forma, os mecanismos envolvidos nas alterações morfológicas e comportamentais.

\section{Alterações nos níveis séricos de neurotrofinas e marcadores inflamatórios através da estimulação de canabinoides}

As neurotrofinas, também chamadas de fatores neurotróficos, são uma família de proteínas capazes de se unir aos receptores das células, promovendo cascatas de sinalizações que desencadeiam funções, como o crescimento, diferenciação e sobrevivência dos neurônios. Tais vias de sinalização intracelular estão envolvidas não apenas na modulação de proteção fisiológica ao neurônio, mas também no desenvolvimento de mecanismos patológicos e perturbações psiquiátricas ${ }^{17}$.

A família das neurotrofinas é formada por NGF, BDNF, neurotrofina-1 (NT-1), neurotrofina-3 (NT-3), neurotrofina-4/5 (NT-4/5), neurotrofina-6 (NT-6) e neurotrofina-7 (NT-7), sendo o NGF e o BDNF os dois mais importantes. O NGF foi a primeira neurotrofina a ser descrita. A mesma é responsável pelo crescimento, sobrevivência e proteção de neurônios contra a apoptose, promovendo a prevenção da degeneração neuronal e regeneração dos nervos periféricos em modelos animais através do alongamento e ramificação axonal ${ }^{18}$. O BDNF é considerado a principal neurotrofina do cérebro, responsável pelas modulações de variadas funções sinápticas, como estímulos à maturação, crescimento, nutrição e integridade neuronal. Exerce papel na neuroplasticidade, gênese, diferenciação, sobrevivência e reparação dos neurônios, o que lhe confere uma função neuroprotetora $^{8}$. O BDNF é produzido pelos núcleos neurais e pelas células da glia, tendo grande expressão no hipocampo, neocórtex, amígdala e cerebelo; dessa forma, pode-se dizer que o BDNF está relacionado a processos cognitivos como aprendizagem e memória adaptativa subjacente ${ }^{7}$.

Diversas pesquisas vêm relacionando a desregulação nos níveis de NGF e BDNF como um dos fatores responsáveis por diversas desordens neurológicas e psiquiátricas, tais como demência, depressão, esquizofrenia, autismo, anorexia, bulimia nervosa, transtorno bipolar e doença de Alzheimer ${ }^{17}$. Por serem considerados fatores de neuroproteção, ambos vêm sendo utilizados como biomarcadores no prognóstico dessas doenças, demonstrando aumento ou diminuição em seus valores séricos ${ }^{19}$. Com o entendimento da importância das funções das neurotrofinas e sabendo que as mesmas são capazes de atravessar a barreira hematoencefática, estudiosos têm realizado mensurações em nível sérico em usuários crônicos da Cannabis, como tentativa de verificar suas respostas na presença do $\Delta$ 9-THC.

Angelucci et al. ${ }^{20}$ realizaram pesquisa na qual dois grupos de pessoas foram separados, sendo um grupo formado por 26 usuários crônicos de Cannabis e outro por 20 voluntários saudáveis, de ambos os sexos e diferentes idades. Utilizando amostras de soro de todos os integrantes, foi realizada uma análise em ensaio imunoenzimático (ELISA), comparando as quantidades de neurotrofinas em uma curva padrão preestabelecida. Nos resultados encontrados, os níveis séricos de NGF dos usuários crônicos foram significativamente menores do que os do grupo controle, porém os níveis séricos do BDNF dos usuários crônicos não apresentaram diferença com os do grupo controle ${ }^{20}$.

D'Souza et al. ${ }^{8}$ também descreveram o comportamento do BDNF durante exposição intravenosa de $\Delta 9$-THC em indivíduos saudáveis que nunca haviam consumido Cannabis e em usuários crônicos da droga. Os integrantes de ambos os grupos realizaram, durante 90 minutos, exames de avaliação de sintomas de abstinência e de sinais vitais, tais como batimentos cardíacos, temperatura corporal e pressão sanguínea. Após esses 90 minutos, os indivíduos receberam doses intravenosas de um placebo de $\triangle 9$-THC e, após duas horas em observação, era administrada uma dose de $0,0286 \mathrm{mg} / \mathrm{kg}$ do $\Delta 9$-THC ativo. Ao longo desse período, foram observados nos pacientes saudáveis aumentos significativos de BDNF, tanto durante a aplicação de placebo quanto na aplicação de $\Delta 9$-THC ativo. Nos usuários crônicos, que já apresentavam níveis basais significativamente baixos da neurotrofina, foram observados níveis séricos constantes da mesma, sem apresentar aumentos ou diminuições significativas ao longo das coletas. Após uma hora da administração de $\Delta 9$-THC no sangue, os níveis basais de BDNF nos indivíduos saudáveis voltaram ao normal e, nos usuários crônicos, continuavam semelhantes aos valores observados no início da pesquisa.

Diante dos dados apresentados, os autores observaram que uma produção reduzida de neurotrofinas foi provocada como uma adaptação ao consumo crônico da Cannabis, resultando em neurotoxicidade ${ }^{20}$. Além disso, a expressão aumentada de BDNF no SNC de não usuários após a exposição ao $\Delta 9$-THC indica uma tentativa rápida de neuroproteção proporcionada por essa neurotrofina ${ }^{8}$. Sugere-se, dessa forma, que uma produção diminuída de neurotrofinas prejudicaria as funções normais dos neurônios, contribuindo para a fisiopatologia de transtornos psiquiátricos ao longo do tempo ${ }^{19}$.

Neste sentido, correlacionando os níveis de neurotrofinas com o desenvolvimento de perturbações psiquiátricas e o uso da Cannabis, alguns autores elaboraram estudos que visam determinar a influência do $\triangle 9$-THC em indivíduos com predisposição ao aparecimento de distúrbios psicológicos. Jockers-Scherübl et al. ${ }^{21}$ elaboraram uma pesquisa na qual testavam a hipótese de que danos à integridade neuronal verificados na esquizofrenia podem ser potencializados pelo consumo de Cannabis e outras substâncias neurotóxicas, resultando em alterações nas concentrações séricas de NGF. Foram mensurados os níveis séricos de neurotrofina em 109 pacientes esquizofrênicos que faziam tratamento farmacológico, comparados com controles saudáveis. Os níveis de NGF de 76 pacientes esquizofrênicos que não consumiam drogas ilícitas $(26,3 \pm 19,5 \%$ pg/mL Cu) 
não diferenciaram significativamente dos níveis obtidos nas 61 pessoas do grupo saudável $(33,1 \pm 31 \% \mathrm{pg} / \mathrm{mL} \mathrm{Cu})$. Os 21 pacientes esquizofrênicos que faziam uso regular de Cannabis ( $\geq 0,5 \mathrm{~g} / \mathrm{dia}$ por pelo menos dois anos) apresentaram aumento significativo de NGF no soro $(412,9 \pm 288,4 \mathrm{pg} / \mathrm{mL} \mathrm{Cu})$ em comparação com controles e pacientes esquizofrênicos que não consumiam Cannabis. Em 12 doentes esquizofrênicos abusadores de Cannabis e outras substâncias adicionais, as concentrações de NGF foram ainda mais elevadas $(2.336,2 \pm 1.711,4 \mathrm{pg} / \mathrm{mL} \mathrm{Cu})$, o que correspondeu às maiores concentrações de NGF endógenos relatados para o ser humano até a data.

Os autores acreditam que as elevações dos níveis de NGF encontrados no soro dos pacientes esquizofrênicos que faziam uso de Cannabis poderiam ser atribuídas a uma interação com o tratamento farmacológico utilizado para combater os sintomas da esquizofrenia. Tal hipótese condiz com uma pesquisa, posteriormente realizada por Schmidt e Duman ${ }^{19}$, a qual confirma que o mecanismo de ação de alguns fármacos antidepressivos seria provocar elevação nos níveis de neurotrofinas como forma de combater a depressão, outro transtorno psicológico. Além disso, Toyooka et al. ${ }^{22}$ verificaram aumentos dos níveis de BDNF em ratos tratados durante cinco meses com antipsicóticos como o haloperidol. No entanto, Jockers-Scherübl et al. ${ }^{21}$ não conseguiram determinar o motivo pelo qual os pacientes esquizofrênicos não usuários de Cannabis não apresentaram diferenças com relação aos indivíduos controles saudáveis. Por exemplo, os pacientes esquizofrênicos poderiam apresentar baixos níveis de neurotrofina por apresentarem reduções nos níveis de plaquetas, que são estruturas que contêm grande quantidade de neurotrofina ${ }^{22,23}$, e o aumento verificado de NGF nos grupos consumidores de Cannabis poderia estar elevado antes do início da doença ou foi posteriormente reforçada pelo consumo consorciado da Cannabis. Apesar das dúvidas existentes, os resultados demonstram que as concentrações séricas de NGF em esquizofrênicos diferem grandemente do consumo prolongado de drogas ilícitas. Sabemos que a Cannabis é um dos fatores de risco para o desenvolvimento da esquizofrenia, pois cerca de 20 consumidores de Cannabis sofreram o primeiro episódio da doença 3,5 anos mais cedo do que pacientes esquizofrênicos que se abstiveram da droga ${ }^{21}$.

Em continuidade, Jockers-Scherübl et al. ${ }^{24}$ desenvolveram uma pesquisa semelhante à anterior, na qual mediram os níveis de BDNF no soro de pacientes que apresentaram seu primeiro episódio de esquizofrenia, sem nenhum uso anterior de antipsicóticos. Os resultados foram comparados com o consumo prévio de Cannabis ou outras substâncias, tais como anfetamina e cocaína. As amostras de soro dos pacientes esquizofrênicos que abusavam de Cannabis e outras substâncias apresentaram valores de BDNF significativamente maiores quando comparados com o grupo controle e o grupo de indivíduos saudáveis usuários de Cannabis.

Os autores concluíram que os níveis aumentados de BDNF no soro não estão relacionados, exclusivamente, à esquizofrenia ou ao abuso de substâncias neurotóxicas em si, pois os pacientes esquizofrênicos que não consumiam Cannabis e os indivíduos saudáveis usuários de Cannabis apresentaram resultados estatisticamente semelhantes aos do grupo controle ${ }^{24}$. Entretanto, a alteração de BDNF pode refletir uma soma das duas condições, demonstrando que o $\Delta 9$-THC poderia causar sérios danos em cérebros de pacientes esquizofrênicos, que, hipoteticamente, já possuem distúrbios na citoarquitetura neuronal e parâmetros bioquímicos cerebrais anormais desde o desenvolvimento fetal. Dessa forma, o consumo de Cannabis por pessoas com formação neuronal vulnerável poderia potencializar lesões neuronais, acentuando e acelerando o aparecimento de esquizofrenia. É importante ressaltar, no entanto, que, apesar da semelhança estatística, os indivíduos saudáveis usuários de Cannabis apresentaram cerca da metade dos valores médios de neurotrofinas verificadas nos indivíduos saudáveis não usuários, indicando uma tendência importante de diminuição da neuroproteção, constatada em estudos anteriores.

Neste sentido, podemos verificar que os resultados verificados acerca das alterações nas neurotrofinas em usuários crônicos de Cannabis foram diferentes daqueles verificados durante exposição intravenosa aguda de $\Delta 9$-THC (Tabela 2). Com exceção dos estudos que avaliaram pacientes esquizofrênicos, usuários saudáveis e crônicos parecem apresentar adaptativamente uma redução nos níveis de neurotrofina, enquanto que indivíduos saudáveis não usuários, quando submetidos a doses intravenosas de $\Delta 9$-THC, apresentam aumento agudo de neurotrofinas. Tal comportamento tem sido interpretado como uma tentativa de proteção neural aguda contra a toxicidade do $\triangle 9$-THC.

Por meio das pesquisas analisadas, podemos considerar também que as neurotrofinas não poderiam ser consideradas específicas para um determinado diagnóstico, mas poderiam ser utilizadas como marcador para determinar a cronicidade de uma

Tabela 2: Alterações séricas nos níveis de neurotrofinas verificadas após exposição intravenosa de $\Delta 9$-THC e consumo de Cannabis sativa isolado ou consorciado com outras drogas

\begin{tabular}{|c|c|}
\hline Autores & Alterações séricas de neurotrofinas \\
\hline D'Souza et al. ${ }^{8 *}$ & $\begin{array}{l}\text { Redução na produção de neurotrofinas } \\
\text { em usuários pesados. Expressão aumentada } \\
\text { de BDNF no SNC de não usuários após } \\
\text { exposição ao } \Delta 9 \text {-THC. }\end{array}$ \\
\hline Angelucci et $a .^{20 * *}$ & $\begin{array}{l}\text { Redução na produção de neurotrofinas, } \\
\text { provocando diminuição dos níveis } \\
\text { séricos de NGF. }\end{array}$ \\
\hline $\begin{array}{l}\text { Jockers-Scherübl } \\
\text { et al. } .^{21 * * *}\end{array}$ & $\begin{array}{l}\text { Elevação dos níveis de NGF proporcional } \\
\text { ao consumo de Cannabis em pacientes } \\
\text { esquizofrênicos. Antecipação de sintomas } \\
\text { de esquizofrenia. }\end{array}$ \\
\hline $\begin{array}{l}\text { Jockers-Scherübl } \\
\text { et al. }{ }^{24 * \star *}\end{array}$ & $\begin{array}{l}\text { Elevação dos níveis de BDNF proporcional } \\
\text { ao consumo de Cannabis em pacientes } \\
\text { esquizofrênicos. }\end{array}$ \\
\hline
\end{tabular}

*Estudos realizados a partir da exposição intravenosa ao $\triangle 9-\mathrm{THC}$; **estudos realizados a partir do consumo crônico de Cannabis sativa; ${ }^{* * *}$ estudos realizados a partir do consumo crônico de Cannabis sativa consorciado com outras drogas em pacientes esquizofrênicos

BDNF: fator neurotrófico derivado do cérebro; SNC: sistema nervoso central; NGF: fator de crescimento neural; $\triangle 9$-THC: delta 9-tetra-hidrocanabinol 
doença e, possivelmente, para um prognóstico. Neste sentido, utilizando o NGF como marcador de cronicidade, estudiosos confirmaram que as neurotrofinas têm seus níveis aumentados em diversas condições inflamatórias. Por exemplo, Giudice ${ }^{25}$ observou que, em algumas doenças ginecológicas, a elevação dos níveis de prostaglandina $\mathrm{E}_{2}$ estimula a produção de NGF e contribui para a percepção de dor e inflamação na endometriose. Concentrações anormais de NGF foram demonstradas também em doenças crônicas, tais como na doença de Behçet ${ }^{26}$ e no consumo crônico de substâncias químicas, tais como opioides perinatais ${ }^{27}$, álcool ${ }^{28}$, nicotina ${ }^{29}$ e cocaína ${ }^{30}$.

A hipótese de Giudice ${ }^{25}$ sobre níveis elevados de PGs possivelmente provocarem estímulos na produção de neurotrofinas condiz com o estudo de D'Souza et al. ${ }^{8}$, os quais acreditam que o aumento verificado de neurotrofinas representam uma tentativa de proteção à toxidade ou inflamação provocada pelo $\Delta$ 9-THC. Diversos estudos têm observado que as PGs apresentam sua síntese e liberação aumentadas durante exposição a canabinoides ${ }^{10,31}$, podendo existir, dessa forma, uma relação entre o aumento de PGs e o aumento agudo de neurotrofinas durante a exposição ao $\Delta 9$-THC. Outras evidências têm demonstrado que a metabolização de endocanabinoides por meio da ciclooxigenase-2 (COX-2) está relacionada com o aumento de marcadores inflamatórios, tais como a produção de $\mathrm{PGE}_{2}-\mathrm{G}$, proporcionando um efeito neurodegenerativo e morte de células nervosas ${ }^{32}$.

Existem, portanto, fortes evidências de que os eicosanoides estão envolvidos em ações no SNC desencadeadas por canabinoides $^{33}$; no entanto, os efeitos dos mesmos sobre os eicosanoides ainda não estão claros. Por exemplo, enquanto estudos associaram neurodegeneração e sintomas de dependência através do aumento da produção de PGs provocada pela estimulação de canabinoides ${ }^{31,32}$, outros verificaram efeitos neuroprotetores através da ativação dos produtos das lipo-oxigenases por meio da estimulação da anandamida, um eicosanoide que mimetiza o $\Delta$ - $\mathrm{THC}^{11}$.

Anggadiredja et al. ${ }^{31}$ desenvolveram uma pesquisa na qual relacionaram a retirada de substâncias canabinoides de seus receptores afins com a desativação da cascata do AA ou de seus produtos e a ocorrência de sintomas de abstinência ao $\Delta 9$-THC. Nesse estudo, camundongos foram expostos diariamente a $20 \mathrm{mg} / \mathrm{kg}$ de $\Delta 8$-THC, congênere do $\Delta 9$-THC, ao longo de seis dias, tempo aproximadamente necessário para a manifestação de dependência da droga ${ }^{31}$. Sabendo que a indução comportamental ao uso de canabinoides está relacionada com a ativação da cascata do AA e consequente aumento da liberação de PGs, Anggadiredja et al. ${ }^{31}$ concluíram que a retirada dos canabinoides - observada por meio da ação do antagonista administrado, bem como com a utilização de diclofenaco - exerceu influência na diminuição dos níveis de PGs, demonstrando abstinência do $\Delta 8$-THC. Os autores sugeriram, então, que, durante a síndrome de abstinência à Cannabis sativa, os níveis de PGs estariam diminuídos, pois os sintomas demonstrados no estudo foram semelhantes aos sintomas observados em abstinência comportamental a essa droga.
Nesse estudo, as manifestações de abstinência ao $\Delta 9$-THC ou seus congêneres, associadas à diminuição da síntese de PGs, parecem demonstrar que a falta de PGs pode ser a razão de um dos efeitos da adaptação crônica do princípio ativo da Cannabis sativa.

Pesquisas que avaliaram a produção de PGs a partir da estimulação de canabinoides em tecidos não cerebrais têm encontrado também diferentes resultados. Enquanto estudos demonstraram aumento da disponibilidade de AA e síntese de $\mathrm{PGE}_{2}$ e $\mathrm{PGF}_{2}$ no tecido uterino ${ }^{34}$, outros verificaram ação anti-inflamatória com inibição da síntese de PGs em cultura de células do cólon humano ${ }^{35}$. Evidências têm demonstrado que a ação anti-inflamatória desencadeada pelos canabinoides através da estimulação de receptores canabinoides, estaria relacionada com a apoptose de células tumorais, diminuição de metástases, diminuição da proliferação celular, analgesia, redução de efeitos colaterais do uso de quimioterápicos etc., por meio da inibição das enzimas $\mathrm{COX}^{33,35-37}$. Efeitos analgésicos têm sido observados também através da diminuição da produção de PGs por meio do metabolismo do óxido nítrico $(\mathrm{NO})^{38}$. É interessante destacar que, independentemente do fato de os canabinoides estarem ou não estimulando a produção de PGs ou LT nesses diferentes órgãos, existe a possibilidade de aplicações positivas quanto ao seu uso clínico.

Neste sentido, a influência que as PGs poderiam exercer sobre as neurotrofinas a partir da estimulação de canabinoides, de forma a provocar neurodegeneração, não está clara. Os diferentes resultados encontrados nesses estudos poderiam ser atribuídos às variadas metodologias utilizadas, tanto em função do tipo de receptor canabinoide do órgão pesquisado (CB1 ou CB2) como em função de diferenças na relação dose-resposta. Essas evidências tornam esse assunto ainda mais complexo e promissor, na medida em que ampliam nossa compreensão dos efeitos deletérios do uso da Cannabis sativa sobre o tecido cerebral, os quais continuam sendo constatados em estudos mais recentes ${ }^{39,40}$, e potencializam a utilização dos canabinoides para fins clínicos e medicinais. Portanto, pesquisas necessitam ser feitas na tentativa de melhor compreender a interação dos canabinoides com as PGs e sua relação com as neurotrofinas.

\section{CONCLUSÃO}

É importante deixar claro que o objetivo do nosso trabalho não foi confrontar as repercussões negativas e positivas que têm sido encontradas com o uso do $\Delta 9$-THC. Atualmente, a discussão a respeito desse assunto envolve diferentes interesses e opiniões de fundo político e ideológico e nosso interesse foi analisar, através de dados da literatura, a relação existente entre respostas neurotóxicas desencadeadas pelo uso da Cannabis sativa e seus componentes com evidências de alterações morfológicas encontradas no tecido cerebral.

Na revisão descrita, podemos observar e analisar diversos estudos voltados para a melhor compreensão dos efeitos do uso da Cannabis sativa ou da exposição crônica e aguda do seu principal 
princípio ativo, o $\Delta 9$-THC. As pesquisas com usuários de Cannabis sativa ou as pesquisas com modelo animal e in vitro apresentaram diversas alterações morfológicas neurais em comparação a situações em que não ocorreu a exposição aos seus componentes, tais como diminuição no número de sinapses, diminuição da densidade neuronal, rupturas dos filamentos de DNA genômico, redução do comprimento dos dendritos, entre outros. Foram observadas também alterações bioquímicas significativas em situações de uso crônico, como redução na produção de neurotrofinas (proteínas responsáveis pela proteção e plasticidade dos neurônios), o que poderia explicar as alterações morfológicas observadas em usuários crônicos de Cannabis sativa. Em indivíduos não usuários, doses intravenosas de $\triangle 9$-THC aumentaram agudamente os valores da neurotrofina, o que é interpretado como uma tentativa de proteção neural contra a toxidade ao $\Delta 9$-THC. Em pacientes esquizofrênicos usuários de Cannabis, as neurotrofinas apresentaram-se aumentadas, possivelmente em virtude do uso consorciado com a medicação utilizada no tratamento. Além das neurotrofinas, o $\triangle 9$-THC atua diretamente nos produtos do AA, como as PGs. Estas têm sua biossíntese aumentada na presença do princípio ativo da Cannabis sativa que, por conseguinte, pode estimular ou desenvolver o processo de inflamação em regiões onde existe maior indução à síntese de PGs. Outros autores também demonstraram a biossíntese diminuída de PGs. Tal fato poderia explicar a manifestação de comportamentos alterados ou de síndrome de abstinência, como depressão, desânimo constante, sentimento de autodestruição, insônia, mal humor, nervosismo e falta de desejo sexual, sintomas estes específicos da falta de PGs no SNC.

Diante desses resultados, tornam-se evidentes, a partir de um grupo de evidências científicas, os efeitos danosos do princípio ativo da Cannabis sativa sobre o tecido cerebral, desencadeando alterações bioquímicas e perdas neurais que poderiam estar relacionadas com a dificuldade de aprendizagem, redução da memória de curto prazo, perda de sentidos, mudança de comportamento etc. Deste modo, o uso crônico da Cannabis não alteraria somente a bioquímica do organismo, podendo causar danos cerebrais, como também poderia antecipar e intensificar distúrbios psicológicos em usuários, especialmente aqueles com predisposição a transtornos mentais. Por outro lado, cada vez mais pesquisas têm verificado que a estimulação de receptores canabinoides está relacionada também com uma série de adaptações que poderiam desencadear benefícios clínicos, dentre elas, a atividade antitumoral e, inclusive, efeitos neuroprotetores. Apesar de esses resultados parecerem contraditórios, diferenças na relação dose-resposta poderiam ser uma das causas dessas controvérsias. Neste sentido, pesquisas futuras devem ser realizadas a fim de ampliar o conhecimento sobre o assunto de forma que interesses científicos predominem nesse debate.

\section{REFERÊNCIAS}

1. United Nations Office for Drug Control and Crime Prevention. World drug report. Geneva: United Nations Publications; 2013.

2. Crippa JA, Lacerda ALT, Amaro E, Filho GB, Zuardi AW, Bressan RA. Efeitos cerebrais da maconha: resultados dos estudos de neuroimagem. Rev Bras Psiquiatr. 2005;27(1):70-8. http://dx.doi.org/10.1590/S1516-44462005000100016

3. Chan GCK, Hinds TR, Impey S, Storm DR. Hippocampal neurotoxicity of $\Delta$ 9-tetrahydrocannabinol. J Neurosci. 1998;18(14):5322-32.

4. Lawston J, Borella A, Robinson JK, Whitaker-Azmitia PM. Changes in hippocampal morphology following chronic treatment with the synthetic cannabinoid WIN 55,212-2. Brain Res. 2000;877(2):407-10. http://dx.doi.org/10.1016/S0006-8993(00)02739-6

5. Schlaepfer TE, Lancaster E, Heidbreder R, Strain EC, Kosel M, Fisch $\mathrm{HU}$, et al. Decreased frontal white-matter volume in chronic substance abuse. Int J Neuropsychopharmacol. 2006;9(2):147-53. http://dx.doi.org/10.1017/S1461145705005705

6. Yücel M, Solowij N, Respondek C, Whittle S, Fornito A, Pantelis $\mathrm{C}$, et al. Regional brain abnormalities associated with long-term heavy Cannabis use. Arch Gen Psychiatry. 2008;65(6):694-701.

http://dx.doi.org/10.1001/archpsyc.65.6.694

7. Shimizu E, Hashimoto K, Watanabe H, Komatsu N, Okamura N, Koike K, et al. Serum brain-derived neurotrophic factor (BDNF) levels in schizophrenia are indistinguishable from controls. Neurosci Lett. 2003:351(2):111-14.

http://dx.doi.org/10.1016/j.neulet.2003.08.004
8. D'Souza DC, Pittman B, Perry E, Simen A. Preliminary evidence of cannabinoid effects on brain-derived neurotrophic factor (BDNF) levels in humans. Psychopharmacology. 2009;202(4):569-78. http://dx.doi.org/10.1007/s00213-008-1333-2

9. Tuszynski MH, Blesch A. Nerve growth factor: from animal models of cholinergic neuronal degeneration to gene therapy in Alzheimer's disease. Prog Brain Res. 2004;146:441-9. http://dx.doi.org/10.1016/S0079-6123(03)46028-7

10. Kozak KR, Crews BC, Morrow JD, Wang LH, Ma YH, Weinander R, et al. Metabolism of the endocannabinoids, 2-arachidonylglycerol and anandamide, into prostaglandin, thromboxane, and prostacyclin glycerol esters and ethanolamides. J Biol Chem. 2002; 277(47):44877-85.

http://dx.doi.org/10.1074/jbc.M206788200

11. Veldhuis WB, van der Stelt M, Wadman MW, van Zadelhoff G, Maccarrone M, Fezza F, et al. Neuroprotection by the endogenous cannabinoid anandamide and arvanil against in vivo excitotoxicity in the rat: role of vanilloid receptors and lipoxygenases. J Neurosci. 2003;23(10):4127-33

12. Wilson W, Mathew R, Turkington $T$, Hawk $T$, Coleman RE, Provenzale J. Brain morphological changes and early marijuana use: a magnetic resonance and positron emission tomography study. J Addict Dis. 2000;19(1):1-22. http://dx.doi.org/10.1300/J069v19n01_01 
13. Matochik JA, Eldreth DA, Cadet JL, Bolla KI. Altered brain tissue composition in heavy marijuana users. Drug Alcohol Depend. 2005; 77(1):23-30

http://dx.doi.org/10.1016/j.drugalcdep.2004.06.011

14. Block RI, O'Leary DS, Ehrhardt JC, Augustinack JC, Ghoneim MM, Arndt $\mathrm{S}$, et al. Effects of frequent marijuana use on brain tissue volume and composition. Neuroreport. 2000;11(3):491-6. http://dx.doi.org/10.1097/00001756-200002280-00013

15. Scallet AC, Uemura E, Andrews A, Ali SF, McMillan DE, Paule $M G$, et al. Morphometric studies of the rat hippocampus following chronic delta-9-tetrahydrocannabinol (THC). Brain Res. 1987;436(1):193-8.

http://dx.doi.org/10.1016/0006-8993(87)91576-9

16. Landfield PW, Cadwallader LB, Vinsant S. Quantitative changes in hippocampal structure following long-term exposure to $\triangle 9$-tetrahydrocannabinol: possible mediation by glucocorticoid systems. Brain Res. 1988;443(1-2):47-62. http://dx.doi.org/10.1016/0006-8993(88)91597-1

17. Allen SJ, Dawbarn D. Clinical relevance of the neurotrophins and their receptors. Clin Sci. 2006;110(2):175-91. http://dx.doi.org/10.1042/CS20050161

18. Madduri S, Papaloïzos M, Gander B. Synergistic effect of GDNF and NGF on axonal branching and elongation in vitro. Neurosci Res. 2009;65(1):88-97.

http://dx.doi.org/10.1016/j.neures.2009.06.003

19. Schmidt HD, Duman RS. Peripheral BDNF produces antidepressant-like effects in cellular and behavioral models. Neuropsychopharmacol. 2010;35(12):2378-91. http://dx.doi.org/10.1038/npp.2010.114

20. Angelucci F, Ricci V, Spalletta G, Pomponi M, Tonioni F, Caltagirone $C$, et al. Reduced serum concentrations of nerve growth factor, but not brain-derived neurotrophic factor, in chronic cannabis abusers. Eur Neuropsychopharmacol. 2008;18(12):882-7. http://dx.doi.org/10.1016/j.euroneuro.2008.07.008

21. Jockers-Scherübl MC, Matthies U, Danker-Hopfe H, Lang UE, Mahlberg R, Hellweg R. Chronic cannabis abuse raises nerve growth factor serum concentrations in drug-naive schizophrenic patients. J Psychopharmacol. 2003;17(4):439-45. http://dx.doi.org/10.1177/0269881103174007

22. Toyooka K, Asama K, Watanabe Y, Muratake T, Takahashi M Someya $\mathrm{T}$, et al. Decreased levels of brain-derived neurotrophic factor in serum of chronic schizophrenic patients. Psychiatry Res. 2002;110(3):249-57

http://dx.doi.org/10.1016/S0165-1781(02)00127-0

23. Yamamoto $H$, Gurney ME. Human platelets contain brain-derived neurotrophic factor. J Neurosci. 1990;10(11):3469-78.

24. Jockers-Scherübl MC, Danker-Hopfe H, Mahlberg R, Selig F, Rentzsch J, Schurer F, et al. Brain-derived neurotrophic factor serum concentrations are increased in drug-naive schizophrenic patients with chronic Cannabis abuse and multiple substance abuse. Neurosci Lett. 2004;371(1):79-83.

http://dx.doi.org/10.1016/j.neulet.2004.08.045

25. Giudice LC. Clinical practice. Endometriosis. N Engl J Med. 2010;362(25):2389-98

http://dx.doi.org/10.1056/NEJMcp1000274

26. Jockers-Scherübl MC, Zouboulis CC, Boegner F, Hellweg $\mathrm{R}$. Is nerve growth factor a serum marker for neurological and psychiatric complications in Behçet's disease? Lancet. 1996;347(9006):982.

http://dx.doi.org/10.1016/S0140-6736(96)91476-2
27. Wu VW, Mo Q, Yabe T, Schwartz JP, Robinson SE. Perinatal opioids reduce striatal nerve growth factor content in rat striatum. Eur J Pharmacol. 2001;414(2-3):211-4. http://dx.doi.org/10.1016/S0014-2999(01)00807-X

28. Aloe L, Tuveri MA, Guerra G, Pinna L, Tirassa P, Micera A, et al. Changes in human plasma nerve growth factor level after chronic alcohol consumption and withdrawal. Alcohol Clin Exp Res. 1996;20(3):462-5. http://dx.doi.org/10.1111/j.1530-0277.1996.tb01076.x

29. Zhang XY, Xiu MH, Chen C, Yang FD, Wu GY, Lu L, et al. Nicotine dependence and serum BDNF levels in male patients with schizophrenia. Psychopharmacology. 2010;212(3):301-7. http://dx.doi.org/10.1007/s00213-010-1956-y

30. McCarthy DM, Zhang X, Darnell SB, Sangrey GR, Yanagawa $Y$, Sadri-Vakili G, et al. Cocaine alters BDNF expression and neuronal migration in the embryonic mouse forebrain. J Neurosci. 2011:31(38):13400-11.

http://dx.doi.org/10.1523/JNEUROSCI.2944-11.2011

31. Anggadiredja K, Yamaguchi T, Tanaka H, Shoyama Y, Watanabe $S$, Yamamoto T. Decrease in prostaglandin level is a prerequisite for the expression of cannabinoid withdrawal: a quasi abstinence approach. Brain Res. 2005;1066(1-2):201-5

http://dx.doi.org/10.1016/j.brainres.2005.10.065

32. Sang N, Zhang J, Chen C. COX-2 oxidative metabolite of endocannabinoid 2-AG enhances excitatory glutamatergic synaptic transmission and induces neurotoxicity. J Neurochem. 2007;102(6): 1966-77. http://dx.doi.org/10.1111/j.1471-4159.2007.04668.x

33. Păunescu H, Coman OA, Coman L, Ghiță I, Georgescu SR Drăghia $F$, et al. Cannabinoid system and cyclooxygenases inhibitors. J Med Life. 2011;4(1):11-20.

34. Mitchell MD, Sato TA, Wang A, Keelan JA, Ponnampalam AP, Glass M. Cannabinoids stimulate prostaglandin production by human gestational tissues through a tissue and CB1 receptor specific mechanism. Am J Physiol Endocrinol Metab. 2008;294(2):E352-6. http://dx.doi.org/10.1152/ajpendo.00495.2007

35. Ruhaak LR, Felth J, Karlsson PC, Rafter JJ, Verpoorte R, Bohlin $\mathrm{L}$. Evaluation of the cyclooxygenase inhibiting effects of six major cannabinoids isolated from Cannabis sativa. Biol Pharm Bull. 2011;34(5):774-8

http://dx.doi.org/10.1248/bpb.34.774

36. Qamri Z, Preet A, Nasser MW, Bass CE, Leone G, Barsky SH, et al. Synthetic cannabinoid receptor agonists inhibit tumor growth and metastasis of breast cancer. Mol Cancer Ther. 2009;8(11):3117-29. http://dx.doi.org/10.1158/1535-7163.MCT-09-0448

37. Guindon J, Hohmann AG. The endocannabinoid system and cancer: therapeutic implication. Br J Pharmacol. 2011;163(7):1447-63. http://dx.doi.org/10.1111/j.1476-5381.2011.01327.x

38. Romero TR, Resende LC, Duarte ID. The neuronal NO synthase participation in the peripheral antinociception mechanism induced by several analgesic drugs. 2001. Nitric Oxide. 2011;25(4):431-5. http://dx.doi.org/10.1016/j.niox.2011.08.002

39. Zalesky A, Solowij N, Yücel M, Lubman DI, Takagi M, Harding IH, et al. Effect of long-term cannabis use on axonal fibre connectivity. Brain. 2012;135(Pt 7):2245-55. http://dx.doi.org/10.1093/brain/aws136

40. Batalla A, Bhattacharyya S, Yücel M, Fusar-Poli P, Crippa JA, Nogué S, et al. Structural and functional imaging studies in chronic cannabis users: a systematic review of adolescent and adult findings. PLoS One. 2013;8(2):e55821. http://dx.doi.org/10.1371/journal.pone.0055821 